\title{
Desempenho e componentes do peso vivo de cordeiros submetidos a diferentes sistemas de alimentação
}

\author{
Performance and live weight components of lambs submitted to different feeding systems
}

\author{
Sérgio Carvalho $^{1}$ Maria de Fátima da Silva ${ }^{2}$ Rudimar Cerutti ${ }^{2}$ \\ Roberto Kieling $^{3}$ Arlei de Oliveira ${ }^{4}$ Maurício Daleastre $^{4}$
}

\section{RESUMO}

O presente trabalho foi conduzido com o objetivo de realizar uma análise do ganho de peso, características da carcaça e componentes do peso vivo de cordeiros submetidos a diferentes sistemas alimentares. Foram utilizados 12 cordeiros de parto simples, machos castrados, sem raça definida, os quais foram divididos em três tratamentos com quatro repetições. Os tratamentos avaliados foram: 1Confinamento; 2- Suplementação em campo nativo; 3“Creep-feeding”. Os cordeiros apresentavam em média 95 dias de idade, quando então, oito cordeiros foram desmamados $e$, os outros quatro, permaneceram com as mães. Após o desmame, os cordeiros foram distribuídos nos respectivos tratamentos, sendo que, nos tratamentos 1 e 2, foram utilizados os cordeiros desmamados e no tratamento 3 os não desmamados. O abate ocorreu quando os cordeiros atingiram em média, 164 dias de idade. Após cada abate, a carcaça e os componentes corporais dos animais foram pesados individualmente, calculando-se sua percentagem em relação ao peso vivo. Os valores observados neste experimento não mostraram haver efeito dos sistemas de alimentação $(P>0,05)$ sobre as variáveis estudadas. As vísceras cheias e a pele são os componentes do peso vivo de maior importância relativa, representando em média $23,55 \%$ e $10,88 \%$, respectivamente. O ganho de peso, as características de carcaça e os componentes do peso vivo são semelhantes entre cordeiros quando desmamados e confinados, desmamados $e$ suplementados em campo nativo ou alimentados ao pé da mãe em sistema de creep-feeding.
Palavras-chave: confinamento, ovinos, suplementação, vísceras.

\begin{abstract}
The aim of the present study was to evaluate the weight gain, carcass characteristics and live weight components from the lambs subjected to different feeding systems. Twelve lambs, castrated males, of no specific breed, were used and divided in three different treatments: 1-Confinement; 2Supplementation in native pasture; 3- "Creep-feeding”. The lambs presented in an average 95 days old, when then, eight lambs had been weaned and the others four remained with the mothers. After the weaning, the lambs were distributed in the respective treatments, being that in treatments 1 and 2, the lambs weaned and in treatment 3 had been used not weaned. The slaughtering occurred when the lambs were an average of 164 days old. After each slaughtering, the carcass and the body parts of the animals were weighed individually. Afterwards, the percentage in relation to the live weight was calculated. The data found for this experiment have not shown effect from the feeding systems tested $(P>0.05)$ on the variables studied. Visceras full and the skin is the components of the live weight of bigger relative importance, representing in average $23.55 \%$ and $10.88 \%$, respectively. The weight gain, carcass characteristics and components of the live weight are similar between lambs when weaned and confined, weaned and supplemented in native pasture or fed to the foot of the mother in system of creep-feeding.
\end{abstract}

Key words: feedlot, sheep, supplementation, visceras.

\footnotetext{
${ }^{1}$ Professor do Curso de Engenharia de Produção (Habilitação Agroindustrial) e Coordenador do Grupo de Estudos em Agronegócios, Centro Universitário Feevale, RS 239, 2755, 93510-250, Novo Hamburgo, RS, Brasil. E-mail: sergiocarvalho@feevale.br. Autor para correspondência.

${ }^{2}$ Professores do Curso Técnico em Agropecuária do Colégio Teutônia, Brasil.

${ }^{3}$ Professor do Curso de Engenharia de Produção (Habilitação Agroindustrial), Centro Universitário Feevale, Brasil.

${ }^{4}$ Aluno do Curso Técnico em Agropecuária do Colégio Teutônia, Brasil.
} 


\section{INTRODUÇÃO}

Nos últimos anos, tem-se observado uma crise no mercado mundial de lã e, em conseqüência, a produção de carne surge como alternativa para os ovinocultores. Com isso, tem-se verificado um número crescente de pesquisas realizadas com a espécie ovina, principalmente no que se refere à produção de carne. Entretanto, pouca atenção tem sido dada aos componentes e órgãos corporais desses animais.

Contudo, deve-se entender que dentro de um sistema intensivo de produção de carne ovina, para que se obtenha máximo rendimento econômico, devese considerar o animal como um todo. Nesse sentido OSÓRIO et al. (1996) citam que, ao sacrificar um animal, além da carcaça, obtêm-se outros componentes do peso vivo, os quais, também são aproveitáveis.

De acordo com OSÓRIO (1992), todos os componentes não carcaça podem ser aproveitados, sendo que alguns deles servem como alimento para população humana, como por exemplo, a cabeça, o fígado, o coração, os rins, os pulmões e o trato digestivo. Uma vez que o peso relativo dos constituintes não carcaça pode chegar até cerca de $60 \%$ da massa corporal do animal vivo, o não aproveitamento adequado destes constituintes além de representar perda de alimento e matéria prima, representa também consideráveis prejuízos econômicos para os produtores de cordeiros, uma vez que a comercialização destes componentes poderia agregar valor à produção ovina (SILVA SOBRINHO, 2001).

Outro aspecto importante a ser considerado é que, conforme JENKINS \& LEYMASTER (1993), os diferentes programas de alimentação utilizados durante o período de crescimento dos animais, podem influenciar o desenvolvimento dos seus órgãos, resultando em alteração nos requerimentos energéticos para manutenção e influenciando a taxa de conversão alimentar. Portanto, o desempenho animal pode ser influenciado pelo crescimento diferenciado dos órgãos e, com isso, tornar-se importante a condução de estudos que realizem uma avaliação dos componentes corporais dos animais.

O objetivo do presente estudo foi avaliar o ganho de peso, as características da carcaça e os componentes do peso vivo de cordeiros submetidos a diferentes sistemas alimentares.

\section{MATERIAL E MÉTODOS}

O trabalho foi conduzido no Setor de Ovinocultura do Curso Técnico em Agropecuária do Colégio Teutônia, no município de Teutônia, Rio Grande do Sul, no período de 19 de setembro a 27 de no- vembro de 2003. O experimento foi realizado mediante parceria entre o Colégio Teutônia e o Centro Universitário Feevale. Foram utilizados 12 cordeiros, oriundos de parto simples, machos castrados, sem raça definida, os quais foram divididos em três tratamentos com quatro repetições. Os tratamentos avaliados foram: 1Confinamento; 2- Suplementação em campo nativo; 3“Creep-feeding”. Os cordeiros apresentavam em média 95 dias de idade, quando então, oito cordeiros foram desmamados e, os outros quatro, permaneceram com as mães. Após o desmame, os cordeiros foram distribuídos nos respectivos tratamentos, sendo que nos tratamentos 1 e 2 , foram utilizados os cordeiros desmamados e no tratamento 3 os não desmamados. Os animais foram submetidos a um período pré-experimental de 21 dias para adaptação as instalações, alimentação e manejo.

No sistema de confinamento, os cordeiros foram estabulados em baias contendo piso ripado, providas de comedouro e de bebedouro, onde receberam a vontade uma alimentação composta por silagem de milho + concentrado, na proporção 50:50, na matéria seca. O concentrado utilizado era constituído por milho quebrado (46,2\%), farelo de soja $(52,0 \%)$ e calcário calcítico (1,8\%). Na suplementação em campo nativo, os cordeiros foram suplementados com 1,5\% do peso vivo, na base da matéria seca, sendo que o concentrado utilizado foi o mesmo do confinamento. Os cordeiros não desmamados permaneceram com as mães em pastagem de campo nativo, onde receberam como alimentação privativa, em um sistema de creepfeeding, uma oferta de 1,5\% do peso vivo, na base da matéria seca do mesmo concentrado oferecido nos tratamentos anteriores. O concentrado utilizado continha $27,5 \%$ de PB, 78,04\% de NDT, 0,78\% de Ca e 0,49\% de P. Todos os cordeiros tiveram acesso a sal comum à vontade. Em todos sistemas alimentares testados, a ração foi oferecida duas vezes ao dia, sendo o horário de arraçoamento as 8:00 e 17:00 horas. No sistema de confinamento, foi observada sobra de $10 \%$.

Todos os cordeiros foram pesados no início e no final do experimento, sendo que para um melhor acompanhamento do desempenho, foram realizadas pesagens intermediárias. O abate ocorreu quando os cordeiros atingiram em média 164 dias de idade. Após cada abate, a carcaça e os componentes corporais dos animais foram pesados individualmente. $\mathrm{O}$ trato digestivo foi pesado cheio e em seguida procedeu-se a separação do rúmen, retículo, omaso, abomaso, intestino delgado e intestino grosso, os quais, foram pesados cheios. Em seguida, realizou-se esvaziamento e minuciosa lavagem destes órgãos que, após escorrimento da água, foram pesados vazios. 
Posteriormente, calculou-se a porcentagem de todos componentes corporais em relação ao peso vivo.

Após pesagem, a carcaça de cada animal foi separada ao meio, de forma simétrica, longitudinalmente, deixando a cola no lado esquerdo. A metade direita da carcaça foi pesada e separada regionalmente nos seguintes cortes comerciais: pescoço, paleta, costilhar e quarto (ou perna). Após a separação regional, os diferentes cortes comerciais foram pesados e sua porcentagem calculada em relação ao peso da carcaça. A separação regional foi realizada segundo OSÓRIO et al. (1998).

O delineamento experimental utilizado foi o inteiramente casualizado, com três tratamentos e quatro repetições. Os dados foram analisados utilizandose o programa Statistic Analysis System (SAS, 1993), sendo submetidos à análise de variância e ao teste $\mathrm{t}$ (Student - PDIFF) ao nível de 5\% de significância.

\section{RESULTADOS E DISCUSSÃO}

Os valores médios para peso inicial, peso final, ganho de peso diário, peso de carcaça quente, rendimento de carcaça quente e pesos e porcentagens de quarto, paleta, costilhar e pescoço, são apresentados na tabela 1. Verifica-se que não houve diferença significativa $(\mathrm{P}>0,05)$ para nenhuma das variáveis estudadas. Quando comparamos o ganho de peso diário dos animais desmamados e confinados ou suplementados em relação aos não desmamados e suplementados em creep-feeding, observa-se que este foi 52,9\% e 41,7\% superior, respectivamente. Com relação ao peso de carcaça quente, verificou-se uma superioridade dos animais confinados de $1,83 \mathrm{~kg}$ e dos suplementados em campo nativo de $1,93 \mathrm{~kg}$, em rela- ção à carcaça dos cordeiros suplementados em creepfeeding ao pé da mãe. Este fator é importante pois, de acordo com FIGUEIRÓ (1979), embora a comercialização se faça em base ao quilo vivo, a medida real de matéria disponível para o consumo estará dada pelos quilos de carcaça resultantes do abate.

Observando os valores encontrados para as proporções de quarto, paleta, costilhar e pescoço, pode-se ressaltar a pouca variabilidade dos diferentes cortes da carcaça entre os sistemas alimentares testados. Os valores encontrados neste estudo são próximos aos obtidos por FRESCURA (2003), que trabalhando com cordeiros cruza Ile de France x Texel, ao pé da mãe, e alimentados em pastagem cultivada de azevém, confinamento sem alimentação privativa ou confinamento com alimentação privativa, verificaram respectivamente $9,2 \%, 9,1 \%$ e $8,7 \%$ para pescoço, $18,6 \%, 19,5 \%$ e $19,3 \%$ para paleta, 39,6\%, 37,3\% e 37,7\% para costilhar e 31,7\%, 34,0\% e 34,1\% para quarto.

Na tabela 2, são apresentados os valores médios, em kg, para sangue, pele, patas, cabeça, coração, rins, fígado, pulmão + traquéia, baço, gordura interna, gordura renal, vísceras cheias, vísceras vazias e conteúdo gastrintestinal dos cordeiros, de acordo com os sistemas de alimentação. Não houve diferença significativa $(\mathrm{P}>0,05)$ entre os sistemas alimentares avaliados em nenhuma das variáveis estudadas. Ao se observar em termos numéricos os valores médios obtidos, verifica-se que, embora não significativo estatisticamente, os animais alimentados no sistema de confinamento tiveram uma maior quantidade de gordura interna e de gordura renal quando comparado aos cordeiros alimentados nos sistemas de suplementação (à campo ou creep-feeding). Isso possivelmente pode ser explicado pelo maior consumo

Tabela 1 - Valores médios para peso inicial (PESOI), peso final (PESOF), ganho de peso diário (GPD), peso de carcaça quente (PCQ), rendimento de carcaça quente (RCQ) e pesos e porcentagens de quarto (QUA), paleta (PAL), costilhar (COST) e pescoço (PESC), de acordo com os tratamentos.

\begin{tabular}{|c|c|c|c|c|c|c|c|}
\hline \multirow{2}{*}{ Variáveis } & \multicolumn{4}{|c|}{ Tratamentos } & \multirow{2}{*}{$\mathrm{F}$} & \multirow{2}{*}{$\mathrm{P}>\mathrm{F}$} & \multirow{2}{*}{$\mathrm{CV}$} \\
\hline & 1 & 2 & 3 & Média & & & \\
\hline$\overline{\text { PESOI (kg) }}$ & 28,00 & 30,40 & 29,35 & 29,25 & 0,20 & 0,825 & 18,60 \\
\hline PESOF (kg) & 42,30 & 43,27 & 38,45 & 41,34 & 0,44 & 0,658 & 18,63 \\
\hline GPD (g/dia) & 298 & 268 & 189 & 252 & 3,12 & 0,093 & 25,16 \\
\hline PCQ (kg) & 18,57 & 18,69 & 16,76 & 18,01 & 0,38 & 0,695 & 19,52 \\
\hline RCQ (\%) & 44,03 & 43,29 & 43,29 & 43,54 & 0,15 & 0,866 & 5,10 \\
\hline QUA (kg) & 2,92 & 3,03 & 2,71 & 2,89 & 0,37 & 0,701 & 18,83 \\
\hline QUA (\%) & 31,41 & 32,49 & 32,48 & 32,13 & 1,09 & 0,375 & 3,69 \\
\hline PAL (kg) & 1,82 & 1,85 & 1,65 & 1,77 & 0,29 & 0,753 & 21,85 \\
\hline PAL (\%) & 19,56 & 19,74 & 19,67 & 19,66 & 0,09 & 0,915 & 3,08 \\
\hline COST (kg) & 3,69 & 3,60 & 3,24 & 3,51 & 0,49 & 0,625 & 19,27 \\
\hline COST (\%) & 39,79 & 38,54 & 38,66 & 38,99 & 0,68 & 0,531 & 4,28 \\
\hline PESC (kg) & 0,86 & 0,85 & 0,75 & 0,82 & 0,52 & 0,614 & 20,46 \\
\hline PESC (\%) & 9,27 & 9,09 & 9,16 & 9,17 & 0,02 & 0,984 & 15,82 \\
\hline
\end{tabular}

Ciência Rural, v.35, n.3, mai-jun, 2005. 
Tabela 2 - Valores médios dos componentes do peso vivo dos cordeiros, em kg, de acordo com os sistemas de alimentação.

\begin{tabular}{|c|c|c|c|c|c|c|c|}
\hline \multirow{2}{*}{ Componentes do peso vivo (kg) } & \multicolumn{3}{|c|}{ Tratamentos } & \multirow{2}{*}{ Média } & \multirow{2}{*}{$\mathrm{F}$} & \multirow{2}{*}{$\mathrm{P}>\mathrm{F}$} & \multirow{2}{*}{$\mathrm{CV}$} \\
\hline & 1 & 2 & 3 & & & & \\
\hline Peso vivo ao abate & 42,30 & 43,27 & 38,45 & 41,34 & 0,44 & 0,658 & 18,63 \\
\hline Sangue & 1,81 & 2,02 & 1,73 & 1,85 & 0,67 & 0,536 & 19,70 \\
\hline Pele & 4,45 & 4,91 & 4,19 & 4,52 & 0,33 & 0,724 & 27,85 \\
\hline Patas & 0,89 & 0,95 & 0,78 & 0,88 & 0,79 & 0,484 & 21,68 \\
\hline Cabeça & 1,48 & 1,58 & 1,38 & 1,48 & 0,56 & 0,589 & 18,03 \\
\hline Coração & 0,16 & 0,16 & 0,15 & 0,16 & 0,18 & 0,837 & 16,24 \\
\hline Rins & 0,11 & 0,13 & 0,10 & 0,11 & 1,53 & 0,268 & 21,10 \\
\hline Fígado & 0,67 & 0,77 & 0,60 & 0,68 & 1,13 & 0,365 & 23,30 \\
\hline Pulmão + Traquéia & 0,75 & 0,81 & 0,70 & 0,75 & 0,42 & 0,668 & 23,24 \\
\hline Baço & 0,061 & 0,059 & 0,047 & 0,056 & 0,65 & 0,544 & 32,49 \\
\hline Gordura interna & 0,66 & 0,41 & 0,39 & 0,49 & 1,47 & 0,281 & 51,89 \\
\hline Gordura renal & 0,28 & 0,14 & 0,15 & 0,19 & 2,00 & 0,192 & 58,12 \\
\hline Vísceras cheias & 9,95 & 11,07 & 8,56 & 9,86 & 1,06 & 0,385 & 24,72 \\
\hline Vísceras vazias & 2,86 & 3,18 & 2,44 & 2,83 & 1,40 & 0,295 & 21,98 \\
\hline Conteúdo gastrintestinal & 7,09 & 7,83 & 6,12 & 7,04 & 0,92 & 0,432 & 26,29 \\
\hline
\end{tabular}

diário de energia e ao menor gasto energético dos animais confinados quando comparados aos demais.

A tabela 3 mostra a proporção dos componentes do peso vivo dos cordeiros em função do peso vivo ao abate. Não houve diferença significativa $(\mathrm{P}>0,05)$ para nenhuma das variáveis estudadas. Podese destacar certa similaridade entre os tratamentos com relação aos componentes do peso vivo avaliados. Tal fato era esperado, uma vez que os animais apresentavam peso e idade semelhante ao abate. A pele e o sangue foram aqueles componentes que apresentaram maior proporção em relação aos demais. Contudo, ao analisarmos a gordura, observamos que, embora não tenha ocorrido diferença estatística entre os tratamentos, o sistema de confinamento proporcionou maior proporção de gordura (interna e renal) quando comparado aos outros sistemas. Isso pode estar relacionado ao aumento da quantidade de gordura depo- sitada na carcaça dos animais. Esse aspecto deve ser destacado, pois é sabido que o excesso de gordura é prejudicial do ponto de vista qualitativo das carcaças de ovinos e, neste sentido, pode haver rejeição do consumidor a este tipo de produto.

Os valores obtidos no presente estudo são semelhantes aos obtidos por FRESCURA (2003), que ao avaliar os componentes do peso vivo de cordeiros cruza Ile de France x Texel alimentados em pastagem cultivada de azevém, confinamento sem alimentação privativa ou confinamento com alimentação privativa, e abatidos com 27,96 kg de peso vivo, verificou valores médios totais de 4,6\% para sangue, $10,4 \%$ para pele, 2,6\% para patas, 3,7\% para cabeça, $0,4 \%$ para coração, 0,3\% para rins, 1,5\% para fígado e 1,6\% para pulmão + traquéia. Com relação à proporção de baço, o valor médio obtido concorda com OSÓRIO et al. (1996), os quais avaliaram os componentes do peso

Tabela 3 - Valores médios dos componentes do peso vivo dos cordeiros, em \%, de acordo com os sistemas de alimentação.

\begin{tabular}{|c|c|c|c|c|c|c|c|}
\hline \multirow{2}{*}{ Componentes do peso vivo (\%) } & \multicolumn{3}{|c|}{ Tratamentos } & \multirow{2}{*}{ Média } & \multirow{2}{*}{$\mathrm{F}$} & \multirow{2}{*}{$\mathrm{P}>\mathrm{F}$} & \multirow{2}{*}{$\mathrm{CV}$} \\
\hline & 1 & 2 & 3 & & & & \\
\hline Sangue & 4,27 & 4,69 & 4,47 & 4,48 & 1,62 & 0,250 & 7,41 \\
\hline Pele & 10,45 & 11,27 & 10,92 & 10,88 & 0,23 & 0,802 & 16,01 \\
\hline Patas & 2,11 & 2,18 & 2,04 & 2,11 & 0,90 & 0,441 & 6,88 \\
\hline Cabeça & 3,51 & 3,64 & 3,61 & 3,59 & 0,75 & 0,501 & 4,45 \\
\hline Coração & 0,38 & 0,37 & 0,40 & 0,38 & 0,70 & 0,520 & 9,98 \\
\hline Rins & 0,27 & 0,30 & 0,26 & 0,28 & 2,75 & 0,117 & 9,28 \\
\hline Fígado & 1,59 & 1,79 & 1,55 & 1,64 & 3,12 & 0,094 & 9,09 \\
\hline Pulmão + Traquéia & 1,77 & 1,86 & 1,81 & 1,81 & 0,38 & 0,696 & 8,55 \\
\hline Baço & 0,14 & 0,13 & 0,12 & 0,13 & 0,88 & 0,448 & 18,44 \\
\hline Gordura interna & 1,61 & 1,02 & 1,00 & 1,21 & 1,00 & 0,404 & 57,43 \\
\hline Gordura renal & 0,68 & 0,35 & 0,38 & 0,47 & 1,53 & 0,268 & 62,25 \\
\hline Vísceras cheias & 23,50 & 25,36 & 22,08 & 23,65 & 2,47 & 0,140 & 8,86 \\
\hline Vísceras vazias & 6,78 & 7,31 & 6,35 & 6,82 & 2,16 & 0,172 & 9,60 \\
\hline Conteúdo gastrintestinal & 16,71 & 18,05 & 15,73 & 16,83 & 1,80 & 0,220 & 10,31 \\
\hline
\end{tabular}


vivo de cordeiros da raça Corriedale criados em condições extensivas de campo nativo e abatidos com peso vivo médio de 29,57 kg, e verificaram uma proporção de baço de $0,13 \%$.

Analisando-se os resultados apresentados na tabela 3 , pode-se destacar a alta participação das vísceras cheias, sendo que representaram em média $23,65 \%$ do peso vivo dos cordeiros ao abate. Deve-se enfatizar a participação do conteúdo gastrintestinal que representou 16,83\% do peso vivo. Esse aspecto é um fator a ser destacado pois, do ponto de vista produtivo, está diretamente relacionado com o rendimento de carcaça e, conseqüentemente, com a maior ou menor disponibilidade de material comestível ao consumidor. O resultado encontrado está de acordo com SAINZ (1996), o qual cita que o rendimento de carcaça depende primeiramente do conteúdo visceral, que corresponde ao aparelho digestivo, podendo variar de 8 a 18\% do peso vivo, principalmente pelo tipo e quantidade de alimentação.

O valor médio obtido neste estudo para porcentagem de vísceras cheias está de acordo com MENDONÇA et al. (2003), que ao compararem borregos criados em condições extensivas, com alimentação exclusiva em pasto nativo, observaram na raça Ideal e Corriedale, respectivamente, valores médios de $23,5 \%$ e $22,7 \%$.

Os resultados referentes aos pesos e porcentagens de rúmen, retículo, omaso, abomaso, intestino delgado e intestino grosso, com conteúdo, constam na tabela 4, e sem conteúdo, na tabela 5. Não houve diferença significativa $(\mathrm{P}>0,05)$ entre os sistemas alimentares para nenhuma das variáveis analisadas. Contudo, podemos constatar menor peso e proporção de rúmen e retículo cheios dos animais não desmamados e suplementados em creep-feeding, em rela- ção aos desmamados e confinados ou suplementados em campo nativo. Provavelmente a permanência dos cordeiros ao pé da mãe levou a uma menor necessidade de ingestão de alimentos sólidos (pastagem), uma vez que na dieta dos cordeiros ainda havia participação de leite ingerido de suas mães. Este aspecto fica evidente ao avaliar-se o peso e proporção destes órgãos sem conteúdo (tabela 5), e verificar-se uma similaridade entre os sistemas alimentares.

Os valores médios verificados no presente estudo para as porcentagens de rúmen-retículo, omaso e abomaso, sem conteúdo, em relação a massa corporal dos animais, estão próximos aos apresentados por CHURCH (1988), o qual cita para ovinos com peso corporal de 38,9kg, valores de $1,79 \%$ para rúmenretículo, 0,15\% para omaso e 0,53\% para abomaso. Está de acordo também com FURUSHO-GARCIA et al. (2003), que, ao avaliarem o peso e a percentagem dos órgãos internos em relação ao peso de corpo vazio de cordeiros Texel x Bergamácia, Texel x Santa Inês e Santa Inês Puros, terminados em confinamento e abatidos com 180 dias de idade, verificaram valores médios de 1,80\% para rúmen-retículo, $0,18 \%$ para omaso, $0,40 \%$ para abomaso.

\section{CONCLUSÃO}

O ganho de peso, as características da carcaça e os componentes do peso vivo são semelhantes entre cordeiros quando desmamados e confinados, desmamados e suplementados em campo nativo ou alimentados ao pé da mãe em sistema de creep-feeding. Entre os componentes do peso vivo que foram avaliados, as vísceras cheias e a pele são aqueles com maior representatividade e são importantes na determinação do rendimento de carcaça.

Tabela 4 - Valores médios para os pesos e porcentagens de rúmen (RUM), retículo (RET), omaso (OMA), abomaso (ABO), intestino delgado (ID) e intestino grosso (IG), com conteúdo, de acordo com os sistemas de alimentação.

\begin{tabular}{|c|c|c|c|c|c|c|c|}
\hline \multirow{2}{*}{ Variáveis } & \multicolumn{3}{|c|}{ Tratamentos } & \multirow{2}{*}{ Média } & \multirow{2}{*}{$\mathrm{F}$} & \multirow{2}{*}{$\mathrm{P}>\mathrm{F}$} & \multirow{2}{*}{$\mathrm{CV}$} \\
\hline & 1 & 2 & 3 & & & & \\
\hline RUM (kg) & 5,43 & 5,72 & 3,81 & 4,99 & 3,05 & 0,0972 & 23,56 \\
\hline RUM (\%) & 12,88 & 13,05 & 10,10 & 12,01 & 3,92 & 0,059 & 13,92 \\
\hline RET (kg) & 0,28 & 0,34 & 0,17 & 0,24 & 2,02 & 0,188 & 50,98 \\
\hline RET (\%) & 0,54 & 0,78 & 0,44 & 0,51 & 2,18 & 0,169 & 39,87 \\
\hline OMA (kg) & 0,20 & 0,22 & 0,20 & 0,21 & 0,13 & 0,878 & 24,18 \\
\hline OMA (\%) & 0,48 & 0,49 & 0,52 & 0,60 & 0,46 & 0,646 & 11,50 \\
\hline ABO (kg) & 0,64 & 0,78 & 0,78 & 0,68 & 0,43 & 0,665 & 38,76 \\
\hline $\mathrm{ABO}(\%)$ & 1,49 & 1,82 & 1,59 & 1,63 & 0,56 & 0,592 & 27,77 \\
\hline ID (kg) & 1,37 & 1,82 & 1,42 & 1,53 & 1,15 & 0,360 & 30,23 \\
\hline ID (\%) & 3,16 & 4,19 & 3,69 & 3,68 & 2,83 & 0,111 & 16,68 \\
\hline IG (kg) & 1,94 & 1,89 & 1,62 & 1,81 & 0,87 & 0,4530 & 20,58 \\
\hline IG (\%) & 4,57 & 4,41 & 4,18 & 4,39 & 0,82 & 0,472 & 9,88 \\
\hline
\end{tabular}

Ciência Rural, v.35, n.3, mai-jun, 2005. 
Tabela 5 - Valores médios para os pesos, e porcentagens, de rúmen (RUM), retículo (RET), omaso (OMA), abomaso (ABO), intestino delgado (ID) e intestino grosso (IG), sem conteúdo, de acordo com os sistemas de alimentação.

\begin{tabular}{|c|c|c|c|c|c|c|c|}
\hline \multirow{2}{*}{ Variáveis } & \multicolumn{3}{|c|}{ Tratamentos } & \multirow[b]{2}{*}{ Média } & \multirow[b]{2}{*}{$\mathrm{F}$} & \multirow[b]{2}{*}{$\mathrm{P}>\mathrm{F}$} & \multirow[b]{2}{*}{$\mathrm{CV}$} \\
\hline & 1 & 2 & 3 & & & & \\
\hline RUM (kg) & 0,76 & 0,79 & 0,62 & 0,72 & 1,43 & 0,289 & 20,87 \\
\hline RUM (\%) & 1,80 & 1,82 & 1,63 & 1,75 & 1,19 & 0,348 & 10,96 \\
\hline RET (kg) & 0,11 & 0,14 & 0,11 & 0,12 & 0,76 & 0,494 & 25,54 \\
\hline RET (\%) & 0,28 & 0,31 & 0,30 & 0,30 & 0,62 & 0,561 & 16,29 \\
\hline OMA (kg) & 0,10 & 0,11 & 0,10 & 0,10 & 1,17 & 0,3544 & 18,10 \\
\hline OMA (\%) & 0,23 & 0,27 & 0,25 & 0,25 & 1,91 & 0,204 & 10,14 \\
\hline $\mathrm{ABO}(\mathrm{kg})$ & 0,23 & 0,27 & 0,25 & 0,25 & 0,83 & 0,468 & 18,88 \\
\hline $\mathrm{ABO}(\%)$ & 0,54 & 0,62 & 0,65 & 0,60 & 1,48 & 0,278 & 16,08 \\
\hline ID (kg) & 0,73 & 0,84 & 0,67 & 0,75 & 0,78 & 0,487 & 26,05 \\
\hline ID (\%) & 1,73 & 1,92 & 1,74 & 1,80 & 0,64 & 0,548 & 15,15 \\
\hline IG (kg) & 0,93 & 1,02 & 0,69 & 0,88 & 2,05 & 0,184 & 26,99 \\
\hline IG (\%) & 2,21 & 2,35 & 1,77 & 2,11 & 3,37 & 0,081 & 15,69 \\
\hline
\end{tabular}

\section{REFERÊNCIAIS BIBLIOGRÁFICAS}

CHURCH, D.C. El ruminant: fisiologia digestiva y nutrición. Zaragoza : Acribia, 1988. 641p.

FIGUEIRÓ, P.R.P. Rendimento da carcaça em ovinos no Rio Grande do Sul. In: JORNADA TÉCNICA DE PRODUÇÃO OVINA NO RS, 1979, Bagé, RS. Anais... Bagé : EMATER-RS, ARCO, SEAGRI-RS, 1979. p.65-69.

FRESCURA, R.B.M. Produção de cordeiros em pastagem cultivada de azevém (Lolium multiflorum Lam.) e em confinamento. 2003. 75f. Dissertação (Mestrado em Zootecnia) - Curso de Pós-graduação em Zootecnia, Universidade Federal de Santa Maria.

FURUSHO-GARCIA, I.F. et al. Componentes corporais e órgãos internos de cordeiros Texel x Bergamácia, Texel x Santa Inês e Santa Inês puros, terminados em confinamento, com casca de café como parte da dieta. Revista Brasileira de Zootecnia, v.32, n.6, p.19921998, 2003. (Supl. 2).

JENKINS, T.G.; LEYMASTER, K.A. Estimates of maturing rates and masses at maturity for body components of sheep. Journal of Animal Science, v.71, n.11, p.2952-2957, 1993.
MENDONÇA, G. et al. Morfologia, características da carcaça e componentes do peso vivo em borregos Corriedale e Ideal. Ciência Rural, Santa Maria, v.33, n.2, p.351-355, 2003.

OSÓRIO, J.C.S. Estudio de la calidad de canales comercializadas en el tipo ternasco según la procedencia: Bases para la mejora de dicha calidad en Brasil. 1992. 335f. Tese (Doutorado em Veterinária) - Universidad de Zaragoza.

OSÓRIO, J.C.S. et al. Componentes do peso vivo em cordeiros da raça Corriedale. Ciência Rural, Santa Maria, v.26, n.3, p. 483-487, 1996.

OSÓRIO, J.C.S. et al. Métodos para avaliação da produção de carne ovina, in vivo, na carcaça e na carne. Pelotas: UFPEL, 1998. 107p.

SAINZ, R.D. Qualidade de carcaças e de carne de ovinos e caprinos. In: REUNIÃO ANUAL DA SOCIEDADE BRASILEIRA DE ZOOTECNIA, 33., 1996, Fortaleza, CE. Anais... Fortaleza : SBZ, 1996. p.3-14.

SAS INSTITUTE. Sas User's Guide: Statistics. version 6.8. Cary, North Carolina, 1993. 956p.

SILVA SOBRINHO, A.G. Aspectos quantitativos e qualitativos da produção de carne ovina. In: REUNIÃO ANUAL DA SOCIEDADE BRASILEIRA DE ZOOTECNIA, 2001. Piracicaba, SP. Anais... Piracicaba : SBZ, 2001. p.425-446. 